\title{
O CONCEITO DE PESSOA em Ricardo de São Vitor
}

THE CONCEPT OF PERSON by Richard of St. Victor

Alfredo S. Culleton *

Data de recepção do artigo: abril/2011

Data de aprovação e versão final: junho/2011.

\begin{abstract}
RESUMO: O conceito filosófico de pessoa, que em outros tempos jogou um papel fundamental no desenvolvimento da teologia, na atualidade joga um papel igualmente importante na concepção de ser humano assim como em muitos debates modernos sobre ética, política e direito. Nos propomos rastrear este conceito tendo como referencia Boécio para imediatamente focaremos o nosso estudo num dos pensadores que com mais detalhe tem tratado este tema chamado Ricardo de São Vitor cuja originalidade é surpreendente ao opor o conceito de substancia ao de existência.
\end{abstract}

PAlaVRas ChaVe: Pessoa, Ricardo de São Vitor, Boécio, existência.

ABSTRACT: The philosophical concept of person, who once played a key role in the development of theology, currently plays an equally important role in the conception of human been as well as in many modern debates about ethics, politics and law. We propose to trace this concept having as a reference Boethius, immediately we will focus our study on one of the thinkers who have dealt with more detail this theme called Richard of St. Victor whose originality is surprising as he opposes the concept of the substance to the one of existence.

KEY WORDS: Person, Richard of Saint Victor, Boethius, existence.

* Doutor em Filosofia pela Pontifícia Universidade Católica do Rio Grande do Sul (2003). Pós-doutorado no Medieval Institute - University of Notre Dame - USA. Professor adjunto da Universidade do Vale do Rio dos Sinos-UNISINOS. Membro do Bureau Científico da Société Internationale Pour Letude de La Philosophie Médiévale (SIEPM). Membro do Conselho Editorialda Editora Unisinos.m@il: alfredoculleton@hotmail.com 


\section{Introdução:}

O conceito filosófico de pessoa, que em outros tempos jogou um papel fundamental no desenvolvimento da teologia, na atualidade joga um papel igualmente importante na concepção de ser humano assim como em muitos debates modernos sobre ética, política e direito. $\mathrm{Na}$ linguagem ordinária os termos pessoa e ser humano são usados indistintamente como sinônimos. Cada ser humano, ou individuo racional para ser mais preciso, é considerado uma pessoa e cada pessoa um individuo racional. Por momentos, parecem nomes intercambiáveis, mas, em outros casos, pessoa é utilizado como uma propriedade ou qualidade do ser humano.

A distinção dos conceitos de Ser Humano e Pessoa não deveria resultar em afirmações equivocas como a de que possam existir seres humanos que não sejam necessariamente pessoas nem que possam existir pessoas independentemente da sua natureza. Nos propomos rastrear este conceito tendo como referencia Boécio para imediatamente focaremos o nosso estudo num dos pensadores que com mais detalhe tem tratado este tema chamado Ricardo de São Vitor cuja originalidade é surpreendente.

\section{Boécio}

Quando falamos de Boécio estamos falando de alguém que tratou sistematicamente o conceito como poucos na historia da filosofia. Os pensadores da Idade Média, e não só os medievais, mas a maioria dos pensadores que trataram sistematicamente o tema, posicionam-se a respeito do conceito de pessoa tendo como referência o conceito desenvolvido por Boécio, no terceiro capítulo do seu Sobre la persona y las dos naturalezas, onde diz: Persona est naturae rationalis individua substantia: "a pessoa é substância individual da natureza 
racional" (Boécio 1979, p. 557). Para chegar a essa definição, Boécio estabelece, em forma decidida e refletida, seu ponto de partida no marco de uma ontologia da essência. A substância divina carece de matéria e de movimento, dirá Boécio: por isso, é algo uno e é o que é, não havendo lugar para acidentes ou movimento; será verdadeiramente uno aquilo no qual não se dá nenhum número, nada fora do que ele é. Ele postula de maneira explícita que pessoa deve ser definida dentro da "natureza essencial" sendo que para ele pessoa não é outra coisa que a individualidade de uma natureza racional. Significa que o individual enquanto tal é o fator propriamente constitutivo da pessoa (Greshake 2001, p. 133). Dito de outra maneira, para Boécio, a essência da pessoa se constitui já na substância racional individual como tal, e não no ato de ser específico e próprio. Dessa maneira, os acidentes e o aspecto relacional próprio e diferente de pessoa para pessoa fica fora da sua definição.

O argumento de Boécio, resumidamente, é o seguinte: dirá ele que entre as substâncias algumas são universais, outras particulares. Universais são as que se predicam de cada uma em particular, como "homem", "animal", "pedra", "madeira", e outras similares que são gêneros ou espécies. Assim, o homem se predica de cada homem, e o animal de cada animal, e a pedra e a madeira, de cada pedra e de cada madeira. Particulares são as que não se predicam de outros, como Cícero, Platão, esta pedra da qual se fez esta estatua de Aquiles ou a madeira com que foi feita esta mesa. De todos esses casos, nunca se predica a pessoa tratando-se de universais, mas somente de singulares e indivíduos. Portanto, conclui ele, se a pessoa dá-se somente nas substâncias, e toda substância é natureza, e não se dá em universais, mas em indivíduos, chegamos à definição de pessoa: Pessoa é a substância individua da natureza racional.

Nesta, como em outras passagens, o acento dado por Boécio para o conceito de pessoa está na essência individual de natureza racional. A natureza racional será a distinção e o que fará que, neste mundo, só humanos possam ser considerados pessoas, o que acaba identificando ambos no sentido 
essencialista de que todo humano é pessoa.

A erudição do autor é extraordinária e vale a pena nos deter nas distinções que dão sustentação ao seu argumento. No Contra Eutychen et Nestorium ${ }^{1}$ ele vai distinguir quatro tipos de natureza. A primeira "natura est earum rerum quae, cum sit, quoquo modo intellectu capi possunt" (natureza pertence aquelas coisas que, desde que existam, podem em certa maneira ser aprendidas pelo intelecto); a segunda, "natura est vel quod facere vel quod pati possit" (natureza é tanto aquilo que é capaz de agir como sobre o qual pode se agir); a terceira "natura est motus principium per se non per accidens" (natureza é um per se e um principio de movimento não acidental) e quarto, "natura est unam quanque rem informans specifica differentia" (natureza é a diferença especifica que dá forma a algo). Seguimos a Milano (1987) ${ }^{2}$ quando diz que esta sucessão de definições não devem ser consideradas como uma mera coleção de conceitos mas entendidos como percurso lógico do menos determinado ao mais determinado, do mais amplo ao mais restrito e é este o caminho de Boécio na conceituação de pessoa.

A quarta definição designa algo essencial, a sua forma, aquilo que faz algo ser o que é a sua diferença específica. Esta última definição parece ocupar o papel central ao distinguir natureza de pessoa no argumento de Boécio contra o Nestorianismo, e reforça a definição de natureza como "a propriedade específica de qualquer substancia"3 assim reduzindo a natureza a sua essência.

Desta maneira, de acordo com Boécio, assim como a natureza é ou substancia ou acidente, e a pessoa não é predicação de acidente, se diz que pessoa é devidamente predicado de substancias e estas podem ser ou particulares ou universais, pessoa não pode ser predicado de universais, mas somente de particulares e individuais ${ }^{4}$.

Mas, diferentemente a Porfirio e à tradição platônica que pretende reduzir a individualidade a uma coleção de acidentes ou particularidades, Boécio busca entender a individualidade como substancializada. Individualidade para Boécio, mesmo sendo perceptível através dos acidentes, consiste em um quid 
proprium na ordem do substancial. O tipo de individuo que uma pessoa é, o é do tipo de individualidade substancial. Ele retoma a clássica distinção aristotélica entre substancia e acidente reconhecendo, assim como o próprio Aristóteles, que aquilo que verdadeiramente é, de maneira absoluta e desqualificada, substancia ou ousía 5 .

\section{Ricardo de São Vitor}

A contribuição deste abade do mosteiro agostiniano de São Vitor, falecido em 1175, é muito pouco conhecida na história da filosofia. Normalmente é incluído dentro da tradição mística e contemplativa do seu predecessor Hugo, mas, enquanto este defende a impertinência da razão e a necessidade da fé, Ricardo, que publica dois importantes volumes sobre a contemplação, Benjamin minor ${ }^{6}$ sobre a preparação da alma ${ }^{7}$, e Benjamin maior ${ }^{8}$, sobre a graça da contemplação ${ }^{9}$, reforça 0 contrário. $\mathrm{O}$ estilo mais escolástico de Ricardo visa dar sustentação à autoridade das escrituras e da patrística dando maior ênfase na argumentação dialética, buscando tenazmente "razões necessárias" para a fé nas pegadas de Anselmo de Canterbury.

É no De trinitate ${ }^{10}$, onde elabora a mais original e esclarecedora formulação da noção de pessoa, tentando situar o problema da pessoa fora das categorias das explicações físicas e com certa independência a respeito do conceito de substancia, como veremos a seguir. $\mathrm{O}$ estudo desta obra, sobretudo do livro quarto, é importante não só do ponto de vista histórico e cronológico da evolução do conceito, mas como uma radicalmente nova tentativa de formulação ontológicoexistencial para o conceito de pessoa.

Desde o ponto de vista da teologia trinitária, a tensão se situa entre uma visão mono-pessoal e uma perspectiva mais social da Trindade. Em termos históricos, Plantinga o formula da seguinte maneira: "a mais recente discussão tende a se afastar das analogias de caráter psicológicas dominantes de Agostinho 
para a analogia Agostiniana do amor refinadas pelo Ricardo de São Vitor no século XII"11. Dirá ele que Agostinho é visto como a principal fonte do que poderia ser chamado de monopersonalismo trinitário, enquanto que Ricardo de São Vitor no ocidente e os Capadócios no oriente seriam considerados as grandes fontes do trinitarismo social.

Cousins $^{12}$ defenderá, seguindo a Tomás, a idéia de que na trindade a incomunicabilidade é decorrente da comunicação da própria natureza divina. Dirá ele que "existencialmente Ricardo se esforça por identificar a individualidade e relacionalidade manifesta na Trindade...e esta manifesta o ideal humano...mas o trágico estado do ser humano torna este ideal difícil de realizar". A tragédia a que ele se refere não é relativo ao pecado, mas a um dado da criação, qual seja, a de ser finito e limitado. Este limite do ser humano é constitutivo da individualidade humana e impede a sua dissolução numa relação. Somente na natureza divina as pessoas poderiam ser totalmente relacionais e a sua individualidade se sustenta nesta relacionalidade.

\section{O método}

A erudição cristã busca o que foi chamado de "intelligentia fidei", isto é, compreender aquilo em que se acredita. A tradição dialética em geral, e Ricardo em especial, buscam isto através da razão. O primeiro movimento neste processo é lingüístico e terá como referência a semântica do credo de Atanásio ${ }^{13}$ e uma tentativa de compreensão racional dos seus termos. Progressivamente ele vai corroborando os dicere por intelligere através da demonstração de que tal dicere é recte ou ao menos rectius. E isto só pode ser demonstrado através da investigação do significado de um determinado dictum. ${ }^{14}$ Esclarecendo palavras e conceitos do Credo, se valendo dos usos que desta nomenclatura fazem Agostinho e Boécio nos seus próprios tratados. Ricardo faz o movimento da linguagem para a realidade através do sentido.

No caso do conceito de persona, palavra chave no texto de Atanásio, ele partirá da generalidade do termo na linguagem 
coloquial e como um conceito do "senso comum" e irá refinando o conceito até convertê-lo numa formulação ontológica. ${ }^{15}$ Ricardo de São Vitor buscará fazer uma análise lógico-semántica de persona a fim de desvendar a constituição ontológica do mesmo.

\section{A definição}

Encontramos em Ricardo duas versões para a sua definição de pessoa, no caso de pessoa divina; a primeira segue os moldes da formulação de Boécio, e a segunda mais extensa. A primeira é a seguinte: "persona divina sit divine nature incommunicabilis existentia"16; uma incomunicável existentia da natureza divina. Definição contundente sobre a qual não se detém demasiado num primeiro momento. $\mathrm{Na}$ versão mais extensa e articulada, dois capítulos mais tarde, diz: "persona sit existens per se solum juxta singularem quemdam retionalis existentie modum"17. Um ser existente por si mesmo como singular modo de existência racional.

Ricardo dirá que a definição de algo só é perfeita se apenas esse algo é delimitado pela definição e se esse algo é completamente definido por ele. Mas a definição que é sempre geral em algum grau, ao mesmo tempo deve ser exata em essa generalidade, isto é, tão geral quanto específica. Este será o argumento para criticar a definição de Boécio, onde a pouca precisão da sua definição torna ela demasiada genérica ${ }^{18}$ ao ponto de se poder entender que Deus enquanto natureza é substância individual, mas isto não pode ser considerado pessoa. Por isso, a incomunicabilidade fará a diferença na nova definição.

\section{A pessoa para além da categoria de substancia}

Ricardo dirá que de modo geral tem sido dados três tipos de acceptiones para persona: a) substância, b) subsistência ou 
hipóstase, e c) as propriedades pessoais ${ }^{19}$. Ele vai abandonar o conceito grego de hipóstasis, termo este que São Jerônimo teria considerado suspeito de conter veneno ${ }^{20}$. Também tenta evitar a expressão subsistentia por causa da sua complexidade e pouca clareza $^{21}$. Prefere termos mais familiares como pessoa e substancia aos quais lhes agregará novas conotações através da sua análise semântica a fim de lhe dar toda a consistência que pretende. Também rejeita as definições de Boécio, como já vimos, e de Gilberto de Poitiers ${ }^{22}$ que distingue as propriedades pessoais dos nomes das próprias pessoas.

A identificação da pessoa com o termo substância como pretendia Boécio não daria conta da identidade pessoal que é, em última instancia, significada pelo nome que a pessoa tem. Por isso, pessoa não pode ser satisfatoriamente definida apenas usando o parâmetro da substância, mas significa algo mais, que é a posse deste ser substancial através de uma propriedade $\operatorname{particular}^{23}$. À pessoa corresponde, para além de ser uma rationalis substantia, uma outra qualificação, que pertence exclusivamente a um, e diferentemente da racionalidade, não pode ser partilhada por uma série de substâncias, e por essa razão é incomunicável ${ }^{24}$. Pessoa significa a realidade mais determinada, distinta e concreta, unus aliquis solus, ad omnibus aliis singulari proprietate discretus ${ }^{25}$. Aqui o termo substância esta mais próximo do papel de espécie do que ao de substancia entendido como particular, esta substancia.

Dirá Ricardo que pessoa designa não tanto as propriedades particulares de alguém como a identidade peculiar do seu nome. ${ }^{26} \mathrm{O}$ autor tem o nome próprio como significando a particularidade da pessoa para dar certa conotação autoreferencial ao termo; e esclarece, se valendo de São Jerônimo, que o conteúdo do nome próprio, isto é, a particularidade implicitamente expressa no nome, deve ser entendida como aquela que constitui a personalidade, isto é, como o significatum de pessoa. A substância é entendida como aquilo que responde à pergunta quid, o que?; pessoa o que corresponde à pergunta quis, quem?, que é sempre um nome próprio. O primeiro sempre corresponderá uma propriedade natural comum e à segunda, 
quis, uma propriedade singular (proprietas singularis) ${ }^{27}$ pela qual alguém é separado de qualquer outro. Certamente pessoa significa substância racional, mas para cada pessoa distinta não se segue que exista um número distinto e correspondente de substâncias racionais, mas o significado próprio e direto de pessoa é o quis.

\section{Existência}

Há no termo existência amplas conotações que merecem atenção. A raiz desta palavra é o diferencial de Ricardo a respeito de todas as outras definições anteriores e será a ponte entre individualidade e relação. Dirá ele que pode ser usado para responder a duas perguntas básicas sobre um ser: o seu o quê? E o seu de onde?, será o quale quid e o unde, ou a sua essência ou obtinentia, ou a sua substantia ou origo. ${ }^{28}$ A existência designará aquilo que tem uma certa substancialidade e que consiste em uma qualidade própria ao mesmo tempo que é dependente.

Ao longo de todo o livro quarto, Ricardo se vale do termo existentia como categoria distintiva, mas é no capitulo 16 que ele trabalha mais minuciosamente o conceito. Para distinguir substância de pessoa vai se valer da distinção entre existência comum e existência incomunicável, aquela existência que é comum a muitos e aquela que é estritamente incomunicável. A primeira corresponde a aquilo que é partilhado entre vários, enquanto a segunda, caracterizada pelo fato de que não pode ser atribuída a mais do que um individuo singular, é constituída de uma proprietas incomunicável. Aquilo que é comum é a substancia animal, racional, et alia, mas aquela proprietas incomunicável é aquilo que só pode convir a uma só pessoa (quae nonnisi uni alicui personae convenire potest) ${ }^{29}$. A existência neste sentido não é uma substância pura e simplesmente, mas uma propriedade determinada que traz em si um princípio originário. Como resultado, a pessoa é constituída de uma propriedade pessoal original que é simplesmente aquilo que faz alguém ser uma pessoa. A propriedade pessoal é aquilo 
que faz alguém ser absolutamente diferente (discretus) de todos os outros. Dirá ele, que pretender que uma personalem proprietatem seja comunicável no seu conteúdo é o mesmo que pensar que uma pessoa possa ser duas e se é duas não teria propriedade particular e não se distinguiria das demais. A conclusão evidente é que a propriedade pessoal é absolutamente incomunicável, quod proprietas personalis omnino sit incommunicabilis ${ }^{30}$ e consiste no que não é comum e não pode ser comum.

Deve ser destacado que a personalem proprietatem não é um acidente distintivo mas é constitutivo da individualidade e da existência incomunicável; é uma propriedade não acidental, é a danielidade de Daniel, aquilo que faz Daniel ser Daniel e que é ele mesmo, não vem de fora ${ }^{31}$.

Podemos dizer com Ricardo que persona é aquilo no qual a natureza existe, como a pessoa humana, que é a natureza humana individual, existe em si mesma. Isto porque a natureza individual que existe é idêntica ao existente, isto é, a pessoa, e é por isso que se pode dizer que aquela substância (ou natureza) existe por ou em si mesmo. A pergunta agora é: como é que isto difere da proposição de Boécio? Para Boécio, pessoa é a natureza racional; pessoa para Ricardo é aquilo no qual a natureza racional existe. Fica claro que nesta definição pessoa e substancia são conceitualmente distintas de tal maneira que pessoa, enquanto pessoa, se afasta da categoria de substância e de uma definição física de pessoa, ao mesmo tempo que ultrapassa a idéia de "sujeito de atributos" ou " conjunto de propriedades", apontando para a pessoa como a portadora de uma natureza e sujeito das suas operações.

O grande esforço de Ricardo é o de tornar possível que tal conceito se ajuste tanto a homens como à pessoa de Cristo que de acordo com a revelação é divina apesar de ter duas naturezas. Faz assim possível que a pessoa seja detentora de naturezas sem risco de perder a sua identidade como no caso de corresponder uma pessoa a cada natureza. 


\section{Incomunicabilidade}

O caráter de incomunicabilidade é o determinante da realidade substancial de uma pessoa dirá Ricardo. ${ }^{32}$ No século quarto, Basílio o Grande e outros padres Capadócios, já tinha indicado a importância da incomunicabilidade ao identificar as propriedades constitutivas da pessoa; no mesmo sentido, Ricardo tendo como ponto de partida a oposição entre a natureza comum e a particularidade do ser humano, também apontará para a incomunicabilidade da identidade pessoal, mas ele explicita e enfaticamente se move desta afirmação àquela da incomunicabilidade da própria existência pessoal em si.

Em termos formais, a pessoa não é mais pensada como algo (aliquid), mas como alguém (aliquis). A atenção não esta colocada sobre a qualidade específica da racionalidade, que é comum a toda pessoa, mas ao absolutamente único de cada pessoa designada unicamente por um nome próprio. Através de uma criativa maneira de usar o termo existere, indicando a constituição essencial de algo e a sua origem ou seu modo de existir substancial, a pessoa é capaz de ser definida de tal maneira que quebra com as limitações de um ponto de vista essencialista, isto é, uma perspectiva que vê a pessoa somente como um tipo de substância. Existentia permite uma distinção entre pessoas (alius) independentemente de uma distinção entre coisas (aliud).

Cada propriedade pessoal, que é formal e constitutiva do ser pessoa, é absolutamente incomunicável ${ }^{33}$ e o constitutivo da pessoa é a sua existência incomunicável (incommunicabilis existentia), e há tantas pessoas como incomunicáveis existências. Existência significa ao mesmo tempo que algo é que traz (de origem) uma certa propriedade. Se essa propriedade é incomunicável, logo a existência é incomunicável, e é precisamente este tipo de propriedade que pertence a o ser pessoa, e que supera e vai além à ordinário noção de substancia.

Pessoa é existência incomunicável. No caso da Trindade há três pessoas divinas em virtude do fato que há três existências que partilham a mesma substancia, unidos no mesmo modus 
essendi, mas diversos no modos existendi. O que conta para a diversidade de pessoas em Deus são as diferentes características pelas quais as pessoas possuem a mesma substância. Estas características distintas constituem o modus obtinentiae que responde à pergunta sobre a origem. A pergunta sobre a origem não descarta o modus essendi, a natureza como uma qualidade ou diferença natural. A incomunicabilidade de alguém é mais do que uma propriedade de origem; esta fundada ao mesmo tempo no existere como no sistere, isto é, na totalidade da sua existentia.

A primeira vista, entre humanos a pergunta pela origem é respondida com algum acidente e é por isso que se apela à idéia de substancia individual como se a individualidade da espécie humana fosse suficiente para ser considerado pessoa. Se pessoa não é simplesmente substantia individua naturae rationalis, a formulação deve ser outra e a idéia de existência no seu duplo sentido nos salva.

\section{Conclusão}

A guisa de conclusão o artigo de Alvarez Turienzo ${ }^{34}$ nos ajuda a entender a grande tensão em torno do conceito de pessoa que estava em jogo no século XII e que vai marcar os séculos subseqüentes. Por um lado, a tradição Boeciana de forte influencia platônica, onde pessoa é um qualificativo de individuo. Um tipo especifico de individuo, uma natureza especialmente dotada pelo fato de ser portadora de razão. Uma coisa entre outras cuja concepção depende de uma cosmologia e se explica por categorias físicas, e em este sentido dirá o autor, naturalista.

Ricardo, por sua vez, fará uma crítica à concepção naturalista e formula o problema de maneira independente do conceito de substância, mudando, desta maneira, o centro da questão. Nada há de comum entre pessoa e substância dirá ele, pois a substância refere a uma propriedade comum enquanto que pessoa a algo que convêm exclusivamente a um, ...Sub nomine 
personae, similiter subintelligitur quardam proprietas quae non convenit nisi uni soli...Proprietas individualis, singularis, incommunicabilis ${ }^{35}$, chega ao individuo sem partir do conceito de substância. Ele contrapõe substancia a existência, onde substância refere ao que é comum e a pessoa ao incomunicável.

Enquanto a posição boeciana insiste na individualidade a partir de uma metafísica naturalista na oposição o uno e o múltiplo, a proposição de Ricardo insiste na totalidade, em relação com uma metafísica centrada na antítese plenitudeindigência, natureza-espírito. $\mathrm{Na}$ perspectiva da filosofia da natureza, pessoa é uma etapa terminal, resultado; se tende a definir a pessoa em termos de física, uma coisa entre outras, inscrita entre uma causalidade e um resultado, no processo da necessidade natural. Na perspectiva da filosofia do espírito a pessoa é um dado inicial, e é compreendida em termos éticos e não físicos; faz parte do mundo do espírito entre uma vocação e uma responsabilidade. É esta a perspectiva mística que imprime o texto de Ricardo.

Se a pessoa como individualidade depende de uma configuração abstrata, a base de universais, o problema é encontrar um princípio de individuação e este será buscado nos gêneros e nas espécies, unidades formais que se realizam em múltiplos sujeitos singulares. Na outra perspectiva, a pessoa é entendida como totalidade e se sustenta numa essência originária onde a individuação é um dado; o problema é determinar aquilo que integra e completa essa realidade.

\section{Referências}

AGOSTINHO DE HIPONA. A Trindade. Trad. do original latino e introd. de Augustinho Belmonte. São Paulo: Paulus, 1994. (Coleção Patrística; 7).

ALVAREZ TURIENZO, Saturnino. Aspectos del problema de la persona en el siglo XII. In Die metaphysik im mittelater. Miscellanea Medievalia. Berlin: Walter de Gruyter \& co. 1963. 795p. (180-183).

AUGUSTINUS HIPPONENSIS. De trinitate. CPL 0329. SL 50-50A (Ed. W.J. Mountain, 1968)

BOECIO, S. Sobre la persona y las dos naturalezas. In: Fernández, Problemata - Rev. Int. de Filosofia. Vol. 02. No. 01. (2011). pp. 11-26. 
Clemente 1979.

BOK, Nico den, Richard de Saint-Victor et la quête de l'individualité essentielle : La sagesse de la daniélité, in : Brigitte-Mirjam BedosRezak and Dominique Iogna-Prat, L'Individu au Moyen Age. Individuation et individualization avant la modernité, (Paris :Aubier, 2005), 123-44.

COUSSINS, E. A Theology of Interpersonal Relations, in Thought 45 (1970) p. 56-85.

The notion of Person in the "De Trinitate" of Richard of Saint Victor. Dissertação nao publicada. Fordham University 1966.

DEN BOK, Nico. Communicating the most high. A systematic Study of person and trinity in the theology of Richard of St. Victor $(\dagger 1173)$ Paris: Brepols, 1996. 532p.

ÉTHIER, Albert Marie. Le 'De trinitate' de Richard de Saint-Victor. Par AM. Éthier, O.P. Paris : J. Vrin, 1939-124p.

GILBERT DE POITIERS. In De Trinitate. Ed. N. M. Häring in The commentaries on Boethius by Gilbert of Poitiers, Pontifical Institute of Mediaeval Studies, Toronto, 1966. ( PL, 64)

MITALAITÉ. K. Entre Persona et Natura : La notion de personne durant le Haut Moyen Âge, Rev. Sc. Ph. Th., 89 (2005), p. 459-484

PLANTINGA, C. Social Trinity and Triteism. In R. J. FEENSTRA \& C. PLANTINGA (eds) Trinity, Incarnation and Atonement. Philosophical and Theological Essays. Notre Dame, 1989. p. 21-48.

RICHARD de SAINT-VICTOR. La Trinité. Edição bilingue Latim-Francés. Introdução, tradução e notas de Gaston Salet SJ. Paris : Les editions du CERF, 1959. 523 p.

\section{Notas}

1 Boethius, Contra Eut I, 25-58. In MICAELLI, Claudio. Studi sui trattati teologici di Boezio. Napoli : M. D’Auria, 1988. 129p.

2 MILANO, A. Persona in teologia, Edizioni Dehoniane, Naples 1984, p. $335,358$.

3 "Hoc ínterim constet quod inter naturam personamque deffirre praediximus, quoniam natura est cuiuslibet substantiae specificata proprietas, persona vero rationabilis naturae individua substantia" Boethius, Contra Eut. IV, 5-9 p. 92.

4 Boethius, Contra Eut. II, 14-49. p. 82-84.

5 Aristóteles. Categorias. Introdução, tradução e notas de Maria José Figueiredo. Lisboa: Instituto Piaget, 2000. 113 p. 
6 Richard de Saint-Victor. Douze Patriarches ou Beniamin Minor. Ed Bilingüe Francês-Latim, Edição crítica e tradução de Jean Chatillon e Monique Duchet-Suchaux. Paris: Lês Editions Du CERF, 1997. 374 p. Cf. PL 196, 1-94, Petit-Montrouge: Migne, 1833.

7 Cf. Chapelle, A. "Les Douze Patriarches, Ou, Benjamin Minor." Nouvelle Revue Theologique, 120: 668-669 (1997): 668-669.

8 Richard de Saint-Victor. De gratia contemplationis ou Beniamin Maior. PL 196, 63-192, Petit-Montrouge : Migne, 1833.

9 Cf. Andres, Friedrich, Privatdozent Dr, Bonn. "Die Stufen Der Contemplatio in Bonaventuras Itinerarium Mentis in Deum Und Im Benjamin Maior Des Richard Von St. Viktor." Franziskanische Studien, 8 (1921): 189.

10 RICHARD de SAINT-VICTOR. La Trinité. Edição bilingue LatimFrancés. Introdução, tradução e notas de Gaston Salet SJ. Paris : Les editions du CERF, 1959. 523 p. Cf. ÉTHIER, Albert Marie. Le 'De trinitate' de Richard de Saint-Victor. Par A-M. Éthier, O.P. Paris : J. Vrin, 1939- 124p.

11 PLANTINGA, C. Social Trinity and Triteism. In R. J. FEENSTRA \& C. PLANTINGA (eds) Trinity, Incarnation and Atonement. Philosophical and Theological Essays. Notre Dame, 1989. p. 21-48.

12 COUSINS, E. The notion of Person in the "De Trinitate" of Richard of Saint Victor. Dissertação nao publicada. Fordham University 1966.

13 O Credo de Atanásio, subscrito pelos três principais ramos da Igreja Cristã (Católicos Romanos, Católicos Ortodoxos e Protestantes), é geralmente atribuído a Atanásio, Bispo de Alexandria (século IV), mas estudiosos do assunto conferem a ele data posterior (século V). O credo de Atanásio, com quarenta artigos, é um tanto longo para um credo, mas é considerado um majestoso e único monumento da fé imutável de toda a igreja quanto aos grandes mistérios da divindade, da Trindade de pessoas em um só Deus e da dualidade de naturezas de um único Cristo.

14 De Trinitate I, 21 p. 98.

15 De Trinitate IV, 6. p. 243.

16 De Trinitate IV 22, p. 282. 
17 De Trinitate IV 24, p. 284.

18 De Trinitate IV 21, p. 278.

19 De Trinitate IV, 3 p. 235. Cf. DEN BOK, Nico. (1996) p. 209.

20 De Trinitate IV, 4 p. 237. Cf. St Jerome, Ad Damascum epist. 15: Patrologia Latina 22, 356. J.P. Migne, Paris.

21 Cf. HIPP, Stephen A. "Person" in Christian Tradition and the conception of Saint Albert the Great. Münster: Aschendorffsche Verlagsbuchhandlung GmbH \& Co., 2001. 565 p.

22 Gilbert de Poitiers. In De Trinitate. Ed. N. M. Häring in The commentaries on Boethius by Gilbert of Poitiers, Pontifical Institute of Mediaeval Studies, Toronto, 1966. ( PL, 64)

23 Significat autem habentem substantiale esse ex aliqua singulari proprietate. DT IV, 19 p. 272.

24 De Trinitate $I V$, c. 6. Alias ergo subintelligitur proprietas generalis, alias proprietas specialis; ad nomen autem personae, proprietas individualis, singularis, incommunicavilis. P. 242.

25 De Trinitate, IV, c. 7 p. 244.

26 De Trinitate $I V$ c. 3 Hieronymus in his verbis non decit personas esse proprietates personarum sed proprietates nominum, hoc est quod proprie sinificant nomina personarum. P 234.

27 De Trinitate $I V$, c. 7. p. 244

28 De Trinitate $I V, 11-13$. p. 250-256.

29 De Trinitate $I V$ c. 16 p. 262.

30 De Trinitate $I V$ c. 17 p. 266.

31 De Trinitate II, cap. 12 p. 130

32 De Trinitate II, cap. 12 p. 130.

33 De Trinitate $I V$, cap. 18 p. 267. "omnis proprietas personalis omnino est incommunicabilis”. Cf. cap. 22. p. 282.

34 Alvarez Turienzo (1963).

35 De Trinitate IV, cap. VI, p. 243. 